\title{
O IMAGINÁRIO SOCIAL DE PROFESSORES DE EDUCAÇÃO FÍSICA DA REDE MUNICIPAL DE ENSINO DE VITÓRIA A RESPEITO DE SUA FORMAÇÃO CONTINUADA*
}

\author{
MSNDO. WALK LOUREIRO \\ Mestrando em educação física pela Ufes \\ Professor dinamizador de educação física em educação infantil pela prefeitura de Vitória \\ (Vitória - Brasil) \\ Membro do Laboratório de Estudos em Educação Física, Centro de Educação Física e Desportos - \\ Lesef/CEFD/Ufes (Vitória - Brasil) \\ E-mail:walk.1@uol.com.br
}

\author{
MS. FRANCISCO EDUARDO CAPARRÓZ \\ Pesquisador do Laboratório de Estudos em Educação Física do \\ Centro de Educação Física e Desportos - Lesef/CEFD/Ufes (Vitória - Brasil) \\ Mestre em educação (PUC-SP) \\ Doutorando em educação (Universidade de Barcelona) \\ E-mail: caparroz.vix@gmail.com
}

\begin{abstract}
RESUMO
O artigo corresponde ao desdobramento de uma pesquisa de iniciação científica que estudou a formação continuada dos professores de educação física que atuam na educação básica do município de Vitória. Vale-se da teoria do imaginário social e do pressuposto metodológico de uma postura qualitativa. Como resultado, apontamos, entre outras questões: que os professores entrevistados enxergam negativamente a descontinuidade do programa de formação conduzido pela Seme; que esses professores não são somente vítimas desse processo, mas também tributários; e que o sistema precisa dialogar com os docentes, sabendo ouvir seus desejos e aspirações, na construção do programa para que ele não seja estéril.
\end{abstract}

PALAVRAS-CHAVE: Formação continuada; imaginário social; educação física escolar.

* O presente trabalho não contou com apoio financeiro de nenhuma natureza para sua realização. Não houve conflitos de interesses para realização do presente estudo. 
Este trabalho é um desdobramento de uma pesquisa de iniciação científica (Pivic/Ufes/CNPq) desenvolvida na Universidade Federal do Espírito Santo (Ufes), entre o segundo semestre de 2006 e o primeiro semestre de 2007, denominada "A formação continuada dos professores de educação física que atuam na educação básica da rede municipal de ensino de Vitória: o imaginário social dos professores".

Valendo-nos das reflexões acerca de estudos de outros pesquisadores que têm pesquisado sobre a formação continuada em educação física, pudemos perceber alguns pontos importantes e comuns que apontavam a demanda da continuidade de estudos dessa temática. O distanciamento entre o âmbito acadêmico-universitário e o âmbito escolar é apontado como fator preponderante no que tange à formação continuada, visto que os professores que atuam na escola percebem que a produção teórico-acadêmica não tem considerado a complexidade da realidade escolar na qual se materializam as práticas pedagógicas da área (Molina; Molina Neto, 200 I; Palafox, 2002; Terra; Pirolo, 2006). Nesse sentido, em seu estudo, Molina e Molina Neto (200 I , p. 83) expressam que os professores argumentam

[... que os conhecimentos postos à disposição pelos pensadores da Educação Física não têm dado respostas satisfatórias aos problemas que enfrentam no cotidiano da escola e das aulas de Educação Física. $\bigcirc$ argumento que sustentou a crítica da grande maioria, quanto às atividades de Formação Permanente, no âmbito da educação física, é que essas têm priorizado novos procedimentos e estratégias didáticas inovadoras, quando, na opinião deles, o que os professores precisam é participar de um processo permanente de reflexão. Alternativa de Formação Permanente por eles reivindicada.

Terra e Pirolo (2006), ao discutirem a formação continuada, manifestam sua apreensão com "o que" e "como" vem sendo produzido pelos pesquisadores sobre a educação física escolar e de que maneira isso tem impactado a prática pedagógica e a formação dos professores dessa disciplina. Essas autoras, em relação aos pesquisadores da área, preocupam-se com o

[... tipo de investigação que estão realizando, uma vez que a educação física continua com as mesmas dificuldades na relação teoria e prática e carente de conhecer, mais de perto, quem são e como são os professores, como e o que fazem e que dificuldades e necessidades possuem no trabalho que realizam. Estar dentro da escola e imbuir-se com uma investigação em seu interior pode não estar significando muita coisa para avançar no sentido de transformar a realidade investigada; pode não significar que se conheçam os professores ou que favoreçam a sua formação. 
Vale destaque, também, para o que apontam Molina e Molina Neto (200 I, p. 82) em relação ao modo como hegemonicamente tem se dado a formação continuada orientada pela

[...] forte presença do modelo centrado na transferência de conhecimento (Freire, 1997), isto é, prepara o [professor] de Educação Física para ser um consumidor de conhecimentos e um docente que aplica o saber produzido pelas agências de formação continuada. Situação que não é um privilégio exclusivo do professor de Educação Física, mas que nesse coletivo, sustenta-se no princípio do colonialismo acadêmico que valoriza pouco o conhecimento que circula e é produzido pelos professores nas suas práticas docentes diárias.

Palafox (2002), ao discutir fatores e motivos que estão implicados nas dificuldades e limitações para a implementação de propostas críticas de ensino da educação física na escola, expressa, com base em pesquisa realizada no contexto da cidade de Uberlândia, que a formação continuada dos professores é um elemento importante dentro da complexidade e da dinâmica que envolvem e movem a prática pedagógica dessa disciplina no âmbito escolar.

Apontando tanto para fatores macroestruturais como também para os microaspectos que orientam e/ou determinam essa prática e, ainda, para a subjetividade dos professores que a desenvolvem, Palafox trata da questão de ações coletivas que envolvem e/ou são desenvolvidas pelos docentes e, nesse sentido, expõe as dificuldades que vão sendo geradas nas relações pessoais e/ou institucionais para a construção de possibilidades para implementação de projetos pedagógicos críticos para a educação física escolar e também de formação continuada de professores. O autor revela, então, que um ponto nevrálgico em relação a tais questões diz respeito à resistência, por parte dos professores, em participar dessa construção. Mas, apesar disso, segundo o autor, vários docentes "tomaram consciência" das condições adversas para o desenvolvimento de um projeto pedagógico orientado por uma perspectiva crítica e também de um processo coletivo de formação continuada, e têm buscado construir o projeto pedagógico e a formação continuada de forma contextualizada, sistemática, constante e original.

Essas considerações, entre outras, despertaram nosso interesse em desenvolver estudos para a compreensão de como é construído o processo de formação continuada dos professores de educação física que atuam na educação básica do município de Vitória. Tais estudos são relevantes pois permitem investigar o que esses docentes pensam a respeito de seu processo formativo, e compreender, em sua globalidade, complexidade e singularidade, a formação continuada em Vitória; a partir dessa compreensão, estaríamos abertos ao diálogo para pensar os programas de formação continuada com o intuito de melhorá-los qualitativamente. 
Tarefa perante a qual nos colocamos mediante o compromisso de retornar os dados e resultados deste estudo aos sujeitos da pesquisa e aos gestores da rede de ensino em questão. Assim, tendo em conta a questão da globalidade, da complexidade e da singularidade, estabelecemos as seguintes perguntas que nos possibilitaram descrever, analisar e interpretar: o que os professores investigados pensam e fazem em relação à sua formação continuada? E, também, como creem que esta deveria ser?

Atribuímos um caráter global às experiências de formação continuada porque elas podem atuar sob diversos fatores, como valorização do magistério, progressão na carreira, elevação da autoestima do professorado, fortalecimento do sentimento de classe, entre outros. Complexo porque não é uma tarefa simples, uma vez que envolve as políticas governamentais, os interesses dos professores, o que a literatura especializada discute, as ações da iniciativa privada, as condições físico-organizacionais que as redes de ensino oferecem aos seus professores, as condições socioeconômicas desses profissionais, o contexto sócio-histórico e político-cultural de cada um deles, caracterizando as objetividades do grupo de professores envolvidos na formação e as subjetividades de cada um dos participantes dos programas. Singular porque cada programa formativo é único em sua natureza e em seu processo de construção, pois é diferente de quaisquer outras iniciativas em prol da formação continuada de professores no país.

\section{O IMAGINÁRIO SOCIAL}

Como a intenção do trabalho era refletir sobre a realidade do professor de educação física em relação à sua formação continuada com base na teoria do imaginário social, assumimos que o olhar que apresentamos neste trabalho é um dos possíveis olhares, até porque o "Imaginário Social não é, pois, reflexo da realidade: é seu fragmento" (FerReIRA; EIZIRIK, 1994, p. 7).

Para que fique clara a intenção da escolha dessa teoria para a compreensão do pensamento, dos desejos e das ações tomados pelos professores de educação física em prol de sua formação continuada, é preciso partir da conceituação do imaginário.

Sabemos, então, que

O termo "imaginário" tem significados diferentes para cada um de nós. Para uns, o imaginário é tudo o que não existe; uma espécie de mundo oposto à realidade dura e concreta. Para outros, o imaginário é uma produção de devaneios de imagens fantásticas que permitem a evasão para longe das preocupações cotidianas. Alguns representam o imaginário como um resultado de uma força criadora radical própria à imaginação humana. Outros o veem apenas como uma manifestação de um engodo fundamental para a constituição identitária do indivíduo (BARBIER, 1994, p. 15). 
Em outras palavras, "O imaginário é também o imaginário da razão ou com a razão. Isto dito, não é menos verdadeiro que essa distinção entre imaginário e razão costuma ser feita para realçar esta e colocar aquele no desvio [...]" (CoELHO, 1994, p. I l0), ou seja, tal diferenciação visa a creditar valor muito maior à razão do que ao imaginário. Portanto, nossa escolha pela teoria do imaginário social tem como um de seus objetivos dar maior relevância ao imaginário pela importância e pelo impacto que essa dimensão do pensamento humano apresenta na vida em sociedade.

Segundo Castoriadis (1982, p. 404), um dos maiores expoentes da teoria do imaginário social, a sociedade é uma autoinstituição, autocriada, ou seja, "é instituição de um magma de significações, significações imaginárias sociais". Por isso, não seria possível fazer qualquer tentativa de conceituação ou atribuição de sentido/ significado ao imaginário social se não partíssemos da existência da sociedade como uma criação do homem como espécie e, por consequência, como instituição que nos torna humanos.

Em suma, queremos deixar claro que nossa investigação corresponde a uma construção que consiste na interpretação de possibilidades, uma vez que o imaginário de que falamos "não é imagem de; é criação constante e essencialmente indeterminada (social-histórica e psíquica) das figuras/formulários/imagens, e somente com base nestas se pode falar de 'algo'. O que nós chamamos 'realidade' e 'racionalidade' são trabalhos dessa criação" (CASTORIADIS, 1993, p. 29, tradução nossa).

Assim, trataremos, neste artigo, das aspirações e dos interesses comuns e conflitantes, que se entrelaçam, dos sujeitos investigados, pois o ser humano não pode existir na vida cotidiana em busca de sua humanização sem estar constantemente interagindo e se comunicando com outros seres humanos.

\section{ITINERÁRIO METODOLÓGICO}

Nossa pesquisa apresenta, como pressuposto metodológico, uma postura qualitativa que lança mão do conceito de indwelling, trabalhado por Polanyi e apresentado por Maykut e Morehouse (1999), que entende o ser humano como o único instrumento suficientemente flexível para captar quão complexas, sutis e em constante transformação são as experiências e as situações humanas dos sujeitos na investigação qualitativa.

Escolhemos a entrevista por entender que ela permite possibilidades de estabelecermos um amplo diálogo com os sujeitos entrevistados, em um momento no qual podem acontecer trocas, quando é permitido compreendê-los melhor. $\mathrm{Na}$ busca pela construção dessa relação comunicativa, procuramos diminuir o risco de 
caracterizar a entrevista apenas como uma ferramenta funcionalista utilizada para interrogar e julgar nossos colaboradores, até porque compreendemos que

\footnotetext{
Investigar o Imaginário Social de um grupo é propor-se a dialogar com seu mistério. Para isso é fundamental que se admita a possibilidade da surpresa, a presença da sombra, do indizível em tudo aquilo que é dizível. E contar com a inseparabilidade entre o conhecimento e a ignorância. E assumir a humildade de um ser que busca aquilo que é escorregadio, que Ihe escapa enquanto conformação (FERREIRA; EIZIRIK, 1994, p. 10).
}

Buscamos conhecer a história da formação continuada oferecida aos professores de educação física pela Secretaria Municipal de Educação de Vitória (Seme). Constatamos que não havia registros impressos, de forma sistematizada e organizada como arquivo, acerca do programa. Havia apenas o depoimento dos próprios professores, ao qual recorreremos para trazer ao conhecimento de nosso leitor detalhes da formação continuada em Vitória.

Rememorando os encontros de formação continuada de educação física, a professora Elis comenta lembrar a ocorrência de

[...] discussões, debates. Os professores levavam encontros, por exemplo, sobre avaliação, [havia] os colegas que tinham conhecimento maior sobre determinado tema que levavam determinadas questões para debate e a gente ia falando e discutindo o que pensava, o que achava sobre aquele determinado assunto.

O docente Caetano lembra que a formação continuada em Vitória começou em 1992, com "duas horas de discussão de debates e tal. Os professores também tinham momentos de 15 em 15 dias que na escola era [sic] com todo mundo. Então essas pessoas que estavam debatendo entre si, dentro de suas áreas, estavam juntas também nas escolas".

Analisamos também o Plano Municipal de Educação de Vitória - ES 200 I /20 I 0 (Plano Decenal), que corresponde ao único documento a que tivemos acesso na Seme e que fazia menção ao programa de formação continuada oferecido aos professores da rede.

Paralelamente, procedemos a uma pesquisa bibliográfica sobre a temática do estudo e descobrimos duas dissertações (DelBONı, 2006; MuGRÁBI, 2005) que retratavam a história do programa de formação da Seme, conforme a ótica daqueles estudiosos que trabalhavam na rede quando da realização de suas pesquisas. Ambos os pesquisadores também se depararam com a falta de informações e registros de programa e projetos que oficializassem as experiências concretizadas.

A escolha pela utilização combinada das entrevistas com a análise documental e a leitura das dissertações ocorreu pelo fato de acreditarmos ser possível, e até necessário, utilizar um universo heterogêneo de técnicas e métodos (GATTI, 200 I) 
e por entendermos que era preciso lançar mão de tratamento multidimensional (ANDRÉ, 200 I) para compreender o fenômeno da formação continuada dos professores de educação física da rede. Sendo assim, buscamos pela triangulação construída por meio das frentes de trabalho descritas conferir maior validade e fidedignidade a nosso estudo.

Conhecidos minimamente muitos aspectos do programa de formação continuada oferecido e conduzido pela Seme, era chegada a hora de construir as questões que norteariam o diálogo com os docentes e, ainda, de definir os critérios para a escolha dos professores que colaborariam com nossa investigação. Estabelecemos como ponto de corte que os sujeitos escolhidos deveriam ser professores efetivos da rede desde, pelo menos, 199| - ano de início dos encontros de formação da Seme - e ter participado dessa experiência enquanto ela perdurou.

Situando o leitor na cronologia dos encontros de formação continuada, sabemos que o programa foi iniciado no ano de 1991, na gestão do Partido dos Trabalhadores (PT), que se deu entre os anos de 1989 e 1992, foi interrompido em 1996 e retomado em 2002, durante o governo do Partido da Social Democracia Brasileira (PSDB). Durante três mandatos, de 1993 a 2004, o PSDB permaneceu na prefeitura, com o PT retornando ao cargo maior do Executivo no município no ano de 2005 e conseguindo a reeleição de seu prefeito para um novo mandato de 2009 até 2012.

Como pudemos perceber, a reativação dos encontros de formação ocorreu na gestão do mesmo partido que os interrompeu, o PSDB. Essa retomada das reuniões de formação deve-se a uma deliberação do Ministério da Educação (MEC) que determinou a implementação dos Parâmetros Curriculares Nacionais (PCN) em todo o país.

Apresentada parte da história do programa e definidos os nossos critérios, escolhemos entrevistar:

a) dois professores lotados em cargos comissionados na Seme, que ministravam o programa de formação continuada aos professores de educação física, quando da realização do estudo;

b) quatro professores de escolas em contextos diferentes, isto é, trabalhando em instituições em locais diferentes e com condições socioculturais distintas'.

I. Apesar de um desses sujeitos - o docente Caetano - não mais participar do programa de formação oferecido pela Seme quando da realização do estudo, ele compôs tardiamente nossa amostra por ter contribuído com o movimento de consolidação do programa de formação continuada do sistema de dentro da gestão do PT e por ter sido citado por quatro dos outros cinco entrevistados como uma figura-chave que poderia favorecer o entendimento das formações continuadas no município. 
Como assumimos o compromisso de manter a identidade de nossos colaboradores em sigilo, todos os nomes que utilizaremos neste espaço serão fictícios². No Quadro I, apresentamos algumas características dos sujeitos na época da pesquisa.

Quadro I: Características dos sujeitos que compuseram a amostra e de seus contextos laborais

\begin{tabular}{|l|l|l|l|}
\hline Nome & Idade* & Tempo de formado* & Situação de trabalho \\
\hline Elis & 47 & 23 & $\begin{array}{l}\text { Atua em bairro nobre, com clientela de } \\
\text { melhor poder aquisitivo }\end{array}$ \\
\hline Chico Buarque & 54 & 29 & $\begin{array}{l}\text { Atua em bairro intermediário, com clientela } \\
\text { de baixo a médio poder aquisitivo }\end{array}$ \\
\hline Caetano & 39 & 17 & $\begin{array}{l}\text { Atua em bairro periférico, com clientela de } \\
\text { baixo poder aquisitivo predominantemente }\end{array}$ \\
\hline Gil & 50 & 31 & $\begin{array}{l}\text { Atua em bairro intermediário, com clientela } \\
\text { de baixo a médio poder aquisitivo }\end{array}$ \\
\hline Tom & 47 & 25 & Atua na Seme em horário integral \\
\hline Gal & 42 & 21 & Atua na Seme na parte da manhã \\
\hline
\end{tabular}

* Tempo em anos.

Recorremos à entrevista semiestruturada por seu caráter flexível e dinâmico, que a coloca em consonância com a perspectiva qualitativa que orientou esta pesquisa (TAYLOR; BOGDAN, 1987). Tendo em conta o aspecto relacional e comunicativo da entrevista, compreendemo-la "submetida às condições comuns de toda interação face a face, na qual a natureza das relações entre entrevistador/entrevistado influencia tanto o seu curso como o tipo de informação que aparece" (SZYMANSKI, 2004, p. I I).

Buscamos evitar uma postura estandardizada e o direcionamento excessivo das questões, concordando assim com Bogdan e Biklen (1994, p. 135) que, se "[...] o entrevistador controla o conteúdo de uma forma demasiado rígida, quando o sujeito não consegue contar sua história em termos pessoais, pelas suas próprias palavras, a entrevista ultrapassa o âmbito qualitativo".

Ao considerarmos e elaborarmos este instrumento de coleta de dados, tivemos em conta nossa necessidade de obter informações valendo-nos de questões concretas, previamente definidas, mas também e simultaneamente nos permitimos flexibilizá-lo a fim de podermos captar e efetuar indagações não elaboradas de an-

2. Nos trabalhos que publicamos a respeito da pesquisa do Pivic/Ufes/CNPq, adotamos nomes de cantores de nossa Música Popular Brasileira como uma homenagem aos docentes que soltaram a voz, ajudando-nos a compreender uma questão que nos era sensível. 
temão (NEGRINE, 1999). Isso possibilitou que o entrevistado tratasse das temáticas abordadas com maior liberdade para elaborar seus pensamentos e também deu ao "entrevistador uma amplitude de temas considerável, que lhe permite levantar uma série de tópicos e oferecem ao sujeito a oportunidade de moldar o seu conteúdo" (BOGDAN; BIKLEN, 1994, p. 135).

○ fundamental para nós era que a entrevista fosse orientada mais para uma conversação entre iguais do que para um intercâmbio formal de perguntas e respostas, pois o pesquisador é o próprio instrumento da investigação, e não os protocolos e roteiros da entrevista. Encontro entre pesquisador e pesquisados na busca da compreensão das perspectivas que os sujeitos entrevistados têm acerca de suas vidas, suas experiências, tal como as expressam com suas próprias palavras (TAYLOR; BOGDAN, 1987).

Vale destacar, conforme Macedo (2004, p. 166), que a entrevista semiestruturada, apesar de sua característica flexível, demanda, sim, certa coordenação e diretividade por parte do pesquisador, "porquanto trata-se de um instrumento com um objetivo visado, projetado, relativamente guiado por uma problemática e por questões de alguma forma já organizadas na estrutura cognitiva do pesquisador".

Nesse sentido, elaboramos um roteiro inicial contendo algumas poucas questões mais fechadas (com caráter mais informativo, acerca de alguns dados sobre os próprios professores entrevistados) e outras descritivas, que tinham por finalidade estimular os entrevistados a esboçar um quadro mais geral sobre acontecimentos, personagens, ações e cronologia do programa de formação continuada oferecido aos professores de educação física, bem como também sobre as suas próprias experiências acerca do mesmo. Este roteiro inicial possibilitou que tais questões descritivas fossem desencadeadoras de um diálogo entre entrevistador e entrevistado que levaram a reflexões e ao aprofundamento das temáticas centrais desta pesquisa, tais como: a história do referido programa de formação continuada (de sua interrupção até sua retomada); e quais os pensamentos e desejos tidos e as ações tomadas pelos professores de educação física a favor de sua formação continuada (TAYLOR; BOGDAN, 1987).

\section{O IMAGINÁRIO SOCIAL DOS PROFESSORES ENTREVISTADOS EM RELAÇÃO À SUA FORMAÇÃO CONTINUADA}

Ao usar como pano de fundo o imaginário social dos professores de educação física, não era nosso objetivo identificar opiniões consensuais que os sujeitos entrevistados pudessem apresentar em seus depoimentos em relação à formação continuada oferecida pela Seme. Vale destacar que, mesmo nos casos de confluência 
de opinião em alguns assuntos, não é possível imaginar que exista uma realidade única, válida para todos os professores de educação física do ensino municipal de Vitória, pois, como alerta Jurjo Torres, citado por Morgado (2005, p. 7I), é

[... preciso ter em conta que a classe docente é integrada por pessoas com ideais, estilos de vida, concepções e modelos de sociedade diferentes, o que permite supor que é difícil [talvez até impossível] encontrar situações em que todos os professores tenham as mesmas afinidades ideológicas e culturais [...].

Apresentada a fundamentação teórica que nos fez optar pelo imaginário social e explicado como procedemos para escolher nossos colaboradores, é necessário destacar que

[... o o Imaginário Social não é a soma, nem tampouco a justaposição de aspirações coletivas. Como um sistema simbólico, o Imaginário Social reflete práticas sociais em que se dialetizam processos de entendimento e de fabulação de crenças e de ritualizações. Produções de sentidos que circulam na sociedade e que permitem a regulação de comportamentos, de identificação, de distribuição de papéis sociais. Isso é vivido de tal forma pelos agentes sociais que passa a representar para o grupo o sentido de verdadeiro [...] (FERREIRA; EIZIRIK, 1994, p. 6-7).

Posto isso, analisaremos, neste texto, algumas questões interessantes que apareceram na fala de nossos colaboradores e que consideramos importantes para a composição do artigo, por nos darem pistas para compreender o imaginário social dos professores entrevistados a respeito de sua formação continuada e do programa oferecido pela Seme.

Justificadas nossas escolhas, identificamos que quatro dos seis professores de educação física entrevistados (Elis, Caetano, Tom e Gal) entendem que a formação continuada em Vitória tem sido tratada como uma política de mandato, e não de governo (Estado), enquanto os demais (Gil e Chico Buarque) percebem essa falta de continuidade como algo normal da mudança de gestão.

Mudanças sempre vão ocorrer, não tem jeito, ao longo da vida da gente. Eu sou professor formado já faz muito tempo e, ao longo da minha experiência como professor da rede, várias mudanças já aconteceram, mas elas têm de ser discutidas para elas avançarem sem causar mudanças ou transtornos que venham a atrapalhar [...], elas têm de ser estudadas com tranquilidade junto com as pessoas que estão envolvidas para que elas mudem positivamente, para que elas avancem e não haja um retrocesso (educador CHICO BUARQUE).

Na opinião da docente Elis, a descontinuidade é uma prática bastante comum, pois ela percebe que os partidos, tanto de direita quanto de esquerda, não têm 
interesse em dar continuidade às práticas e aos projetos que foram iniciados nos mandatos dos prefeitos aos quais aqueles fizeram oposição.

Eu trabalhei na Secretaria de Educação na época do PT, que detonou com os projetos excelentes que tinham lá dentro, eu me lembro que a gente tinha um projeto interessante acontecendo e acabaram porque tinha que começar tudo do zero. Perde-se um tempão começando tudo do zero de novo, tem que se inventar a roda de novo e aí entra o PSDB e acaba tudo com o que o PT construiu, começa tudo do zero de novo, isso é um equívoco que acontece [...] (docente ELIS).

Portanto, a maioria desses educadores avalia a falta de continuidade da formação continuada propiciada pelo sistema municipal como um fator negativo. Para eles, o que parece estar faltando é uma sólida política para que as formações avancem e não fiquem apenas como ações pontuais de administradores do poder público.

Consideramos importante que cada docente se comprometa com sua formação continuada e com a de seu grupo não como uma ação individual, mas coletiva, que os ajude a progredir e a evoluir não apenas como profissionais da educação, mas como seres humanos, como pessoas. Cremos que os educadores precisam unir-se com sindicatos, movimentos sociais, associações de pais e alunos, organizando-se na luta por uma educação qualitativamente melhor, que também inclua maiores recursos e tempo, garantidos por legislação específica, para investimento na formação continuada dos docentes.

Na opinião do docente Caetano, um dos papéis que ele percebia existir no início da formação continuada em Vitória era

Fortalecer e cobrar, descobrir dificuldades comuns que tem a ver com a política educacional, se organizar e até falar um pouquinho, os mais enraizados no sindicato falar um pouquinho o que se estava sendo falado no sindicato, o próprio sindicato aproveitava esses momentos para fazer isso, pedia cinco minutos para estar falando [sic] da política educacional.

Sabemos, contudo, que essa não é uma tarefa fácil ou simples, especialmente se levarmos em conta, na última década, o que parece ser o enfraquecimento dos órgãos representativos da classe trabalhadora (COSTA, 2007; FERREIRA, 200 I), o que pode ser constatado se observarmos as dificuldades destes em mobilizar os grupos por eles representados e a maneira tímida de atuação do movimento sindical na luta pela conquista de alguns direitos para os trabalhadores como, por exemplo, a redução da jornada de trabalho (FreITAS, 2005).

Faz-se necessária a construção de programas de formação continuada não apenas como processos técnico-burocráticos, mas também como processos políticos que atendam ao interesse coletivo e possibilitem aos educadores compreender 
como as condições macroestruturais conduzem seu trabalho, tornando-os, assim, capazes de buscar possibilidades de superar esses condicionamentos.

Outra questão interessante que apareceu na fala de todos os entrevistados é que eles consideram importante que a formação continuada seja construída em dois momentos distintos, mas complementares: no primeiro, com docentes das demais disciplinas escolares para o estabelecimento de discussões amplas a respeito da instituição escolar e da sociedade em que vivemos - qual a função da escola; qual o conceito de cidadania da escola; que cidadão se pretende formar; que sociedade é esta na qual estamos vivendo; direitos e movimentos sociais, políticas públicas, dentre outros; no segundo momento, debates entre seus pares da educação física sobre questões específicas da área, como legitimidade da educação física, avaliação, conteúdos, dentre outros.

Há momentos que é necessário discutir com seus pares, professores de EF, que tem problemas parecidos, mas há momentos que se precisa discutir no geral [...] (professor CAETANO).

Tanto os encontros específicos são importantes, como os encontros de uma maneira geral com todas as áreas. Eu acho que um enriquece o outro e que a gente pode ter os momentos específicos e pode ter também um momento geral onde todas as áreas da escola vão estar discutindo, vão estar socializando e vão estar enriquecendo o trabalho dentro da escola, então eu acho que tanto o momento específico como o momento geral dentro da escola é importante (educador GIL).

Defendemos esses encontros como um bom momento para trabalhar com uma concepção de formação continuada para além da prática reflexiva (CARVALHO; SIMÕES, 2002), que corresponde não apenas ao trabalho reflexivo do professor baseado numa práxis pedagógica, mas ao relacionamento da sua prática com o contexto social maior, que consiste em um projeto capaz de formar "um profissional de caráter amplo, com pleno domínio e compreensão da realidade de seu tempo, com desenvolvimento da consciência crítica que lhe permita interferir e transformar as condições da escola, da educação e da sociedade [...]” (FreitAS, 2002, p. 139).

O interesse demonstrado pelos docentes vai na mesma direção da construção da escola em que acreditamos, qual seja: aquela capaz de interferir na história de vida dos indivíduos que a frequentam, ajudando a construir um futuro justo para os necessitados. Afinal, que possibilidade os professores de educação física ou de qualquer outra disciplina têm para intervir nessa realidade, se seu processo de formação continuada for realizado separadamente do dos demais docentes, sem se discutir as questões macrossociais que interferem em e impactam suas práticas pedagógicas?

Uma questão interessante, e que nos surpreendeu, foi que os quatro docentes lotados em sala de aula (Elis, Chico Buarque, Caetano e Gil) consideraram 
importantes as deliberações vindas da Seme. Contudo, eles são enfáticos ao afirmar que essa relação deve-se dar em uma via de mão dupla, isto é, eles não têm maiores problemas com as determinações do sistema, desde que exista um diálogo no qual o docente não apenas tenha o direito de falar, mas em que ele seja realmente ouvido.

Nós enquanto profissionais colocamos que não pode vir nada de cima para baixo. Eu não concordo, acho que tem de vir de cima para baixo, agora é preciso também estar mostrando para o sistema se aquilo ali é bom ou não, simplesmente dizer não, não adianta (docente CHICO BUARQUE).

A professora Elis também compreende ser necessário um momento no qual as pessoas que estão à frente do sistema se posicionem, explicitando seu ideal para a educação como um todo no município. Ela relata ainda que, quando foi retomada a formação continuada, os professores de educação física mais ouviam do que falavam e que esses momentos foram importantes para ampliar a visão dos professores participantes (que faziam as pontes refletindo sobre os assuntos que ali eram tratados com base em suas experiências); mas que, em seguida, quando o grupo construía uma opinião fundamentada sobre os temas, os docentes não deixavam de debatê-los.

Nós [re]começamos ouvindo sim, não tem problema nenhum em ouvir às vezes, porque você precisa ouvir às vezes para isso, não para ouvir e bater palma e falar amém, porque não tem nenhuma pessoa ali que não tenha saberes, que não tenha conhecimentos anteriores bem amplos, para daí ouvir e saber analisar [...] Então é legal você ouvir pessoas que estudaram determinados assuntos mais a fundo, mesmo que ela [sic] fale e você não compreenda, que fique muita coisa, mas às vezes alguma coisa fique para te instigar a ir atrás de outras, eu acho fundamental também, e começamos em muitos momentos assim. E, a partir dali, a gente debatia e discutia e fomos criando a nossa filosofia (professora ELIS).

Nesse sentido, é possível perceber o desejo do professor de ser visto como sujeito respeitado e estimulado a participar deliberativamente no processo educacional ${ }^{3}$.

Portanto, as formações organizadas pela Seme podem ser transformadas em um momento muito importante de debate para que o professor não somen-

3. A esse respeito, chamamos a atenção para uma grande pesquisa realizada nos Estados Unidos da América, na década de 1970, que concluiu que os professores possuíam um jeito próprio para dar significado aos assuntos tratados nos programas de formação docente aos quais eram submetidos (HERNÁNDEZ, 2004). Não mais vistos como "uma folha em branco a ser preenchida com novos conhecimentos" (FALSARELLA, 2004, p. 172); foi a partir daí que o professor deixou de ser considerado mero executor dos programas planejados pelas instâncias superiores e passou a ser percebido como um agente deliberativo de fundamental importância para o processo educativo. 
te conheça a proposta oficial do sistema, mas ajude a (re)criá-la, haja vista que "conhecer apenas não basta [...] não garante que o professor tenha condições de materializar determinada proposição, pois tal materialização requer um processo lento de erros, acertos, ajustes; de diálogos, reflexão, troca de experiências [...]" (CAPARRóz, 200I, p. 205).

Apesar de atualmente não haver muitos professores contratados na rede municipal de ensino de Vitória, a incidência de um grande número de professores com contrato temporário de trabalho trouxe sérios problemas para o programa de formação conduzido pela Seme em um passado recente, quando, na avaliação da docente Elis, o quadro de educadores de educação física contratados chegou a cerca de $60 \%$ do total. O problema, segundo o educador Gil, era que, todo início de ano, o programa de formação tinha de começar do zero novamente para dar prosseguimento, para situar os professores recém-contratados, o que tornava o início da formação desestimulante para os professores efetivos com alguns anos de trabalho na rede.

Os professores entrevistados possuem opiniões muito próximas de que a formação continuada é importante por ser uma boa oportunidade para que eles se alimentem de novos saberes, competências e habilidades, e útil por nela ser possível analisar suas práticas pedagógicas pela ótica de outros professores, além de eles poderem aprender coisas novas com os colegas que realizam outras práticas.

As críticas mais contundentes em relação às formações oferecidas pela Seme, até o período em que realizamos nossa pesquisa, isto é, até o primeiro semestre de 2007, para além daquelas já trabalhadas neste texto, são feitas pelos educadores Caetano, Chico Buarque e Elis, e aparecem tangencialmente nas falas, ora de um, ora de outro, dos três professores entrevistados, referindo-se: à falta de diálogo do pessoal da Secretaria com os professores para definir não apenas o tipo de formação continuada que se deseja, mas também os assuntos importantes a serem discutidos nos encontros (docente Caetano); a busca da economia de recursos, deixando-se de investir, por exemplo, em parcerias com a Ufes na assessoria aos professores que se reuniriam em pequenos grupos (professora Elis); a não realização de eventos nos quais os professores possam debater questões específicas da área (educador Caetano); a realização de um número excessivo de oficinas, ao invés de aprofundar os conteúdos teoricamente (educadora Elis); e a falta de intercâmbio deles com professores de outras redes de ensino e até mesmo com docentes da Ufes (docente Chico Buarque).

Além dos encontros oferecidos pela Seme, todos os professores revelaram participar de seminários e simpósios sempre que possível. A docente Elis participa ainda de um grupo de estudo formado por três professoras de educação física 
de escolas próximas a que ela trabalha que se reúne uma vez por mês em seus horários de planejamento, enquanto o educador Caetano também utiliza parte de seu tempo de planejamento para estudar e debater com um professor de história assuntos pertinentes à educação física e à escola como um todo.

Analisando os relatos dos educadores investigados, a Seme parece possuir uma visão restrita da formação continuada, entendendo-a, quase exclusivamente, como reuniões entre os professores da rede e cursos de pós-graduação, já que eles desconheciam qualquer docente que estivesse deslocado para a realização de algum estudo ou projeto de extensão, dentre outros, que pudessem influenciar sua prática.

Apesar de constar no Plano decenal que os programas de formação continuada oferecidos pela rede devem garantir o "desenvolvimento da pesquisa como princípio de formação do professor" (VITÓRIA, 2003, p. 45), a Seme parece entender como pesquisa somente as atividades que são desenvolvidas nos programas oficiais de pós-graduação, especialmente o mestrado e o doutorado.

Mesmo existindo na Secretaria, de acordo com a docente Gal, um critério para a concessão de uma ajuda de custo, prioritária ao professor da rede, para que ele possa apresentar trabalhos de sua autoria em eventos, na visão do docente Chico Buarque, esse custeio depende de a publicação contemplar os interesses dos gestores do sistema.

Entendemos que a participação dos docentes em congressos, seminários e encontros profissionais apenas é uma forma pouco significativa e fragmentada de formação continuada (AQuINo, 2002). Entretanto, defendemos o custeio integral da participação dos professores nesses tipos de eventos não apenas porque os educadores que deles participam podem conhecer outras práticas docentes, mas também porque essa prática pode aumentar a autoestima de um professor que, tendo seu trabalho (re)conhecido e avaliado por outros docentes, se sente, assim, mais valorizado pela rede em que atua.

A última questão observada na pesquisa refere-se à necessidade de haver uma maior proximidade entre a Ufes e a rede municipal de ensino de Vitória, já que, do ponto de vista do educador Chico Buarque, os professores são usados nas pesquisas e não recebem retorno que contribua com a dinâmica escolar.

Nesse ponto, é preciso tomar muito cuidado, pois alguns professores demonstraram o desejo de que o pesquisador "veja o que está acontecendo, faça uma leitura, uma análise e dê retorno" (docente Eıı), e ainda que ele não dê apenas "um retorno muito elementar, [que] fica muito no campo da teoria [...] chega depois lá [e diz:] 'olha, eu entendi isso, a gente analisou isso', e daí?" (docente GAL).

Se ainda existem professores esperando que as pesquisas legitimem seu trabalho e até mesmo que tragam receitas "infalíveis", aplicáveis integralmente em 
sua prática docente, reafirmamos nossa crença de que o pesquisador não tem a função de "ensinar" ao professor de sala de aula um modo "correto" de trabalhar, tampouco conferir um "selo de qualidade" que garanta que estes e aqueles docentes são bons ou maus professores. Seu objetivo é ampliar o horizonte e as possibilidades de trabalho com a construção de propostas e teorias. Mas, para que essa produção teórica seja realmente construtiva, o professor da educação básica precisa compreender, de uma vez por todas, que ele "não deve aplicar teoria na prática e, sim, (re)construir (reinventar) sua prática com referência em ações/experiências e em reflexões/teorias. É fundamental que essa apropriação de teorias se dê de forma autônoma e crítica, portanto, como ação de um sujeito, de um autor" (CAPARRÓz; BRACHT, 2007, p. 27).

\section{CONSIDERAÇÕES FINAIS}

Desenvolvemos, aqui, elementos que apresentam uma parcela dos pensamentos, desejos e ações dos professores de educação física entrevistados em relação à formação continuada oferecida pela Seme, que acreditamos poderem contribuir na melhora qualitativa do programa estudado.

Para que esse objetivo não ficasse apenas no campo das intenções, realizamos o retorno dos resultados alcançados aos gestores daquela Secretaria imediatamente após a concretização de nossa pesquisa. Destaque seja dado para a disponibilidade, de nossa parte, para o debate das ideias em relação ao referido programa de formação continuada com base neste estudo. Até a presente data, a referida Secretaria não estabeleceu conosco nenhum tipo de contato para discutir o estudo realizado.

Entendemos que são necessários novos estudos que aprofundem e sistematizem a reflexão sobre o modo como os docentes Brasil afora percebem os programas de formação continuada oferecidos por seus sistemas de ensino e também quais as aspirações daqueles docentes que não possuem essa prática sistematizada por suas redes.

Contudo, apesar de sabedores da não existência de soluções fáceis para a melhora qualitativa do programa de formação continuada estudado ou de qualquer outro do país, não podemos nos furtar de comentar que os professores entrevistados enxergam de maneira negativa a falta de continuidade no programa de formação continuada propiciada pelo sistema municipal de educação. Devemos destacar que eles não são apenas vítimas desse processo, mas também tributários. Assim, ou se unem com seus pares e buscam negociar coletivamente, por meio de sua instância representativa, o sindicato, soluções para essa situação, ou vão continuar a esperar a formação como dádiva, como benfeitoria, e não como direito conquistado que 
precisa ser mantido e aperfeiçoado. Para que a formação continuada não se torne estéril, é preciso que seja aberto um canal de diálogo com os docentes das demais disciplinas para que sejam debatidos os temas amplos e as questões macrossociais que impactam o trabalho docente. Finalmente, os responsáveis pelos sistemas de ensino precisam dialogar e saber ouvir os desejos e aspirações dos docentes que, sem sombra de dúvidas, serão os principais responsáveis em conduzir com êxito as propostas de ensino do sistema, mas isso somente será possível se esses docentes tiverem condições psicológicas, materiais, financeiras, acadêmicas e didático-pedagógicas favoráveis.

The imaginary social one of teachers of physical education of the municipal public schools of Vitória regarding their continued formation

ABSTRACT: The paper is about the development of a scientific initiation research that studied the continuing formation of Physical Education teachers working with elementary education in the city of Vitória. It is based on the social imaginary theory and methodological assumption of a qualitative posture. As result, it mentions, among other issues: that the teachers who were interviewed see negatively the non-continuity of the formation program conducted by Seme, but evaluate themselves as not only victims of the process, but also tributaries; that the system needs to dialogue with the teachers, knowing how to listen to their wishes and aspirations, in the construction of the program so that it does not become sterile. KEY WORDS: Continuing formation; social imaginary; physical education school subject.

\section{El imaginario social de maestros de la educación física del municipio de Vitória con respecto a su formación continuada}

RESUMEN: El artículo corresponde al desdoblamiento de una investigación de iniciación científica que estudió la formación continuada de maestros de educación física que actúan en la educación básica de la ciudad de Vitória-ES, Brasil. Se basa en la teoría del imaginario social y del supuesto metodológico de una postura cualitativa. En los resultados, apuntamos, entre otras cuestiones: que los maestros entrevistados perciben negativamente la discontinuidad del programa de formación desarrollado por la Seme; además evalúa que ellos no son solamente víctimas de dicho proceso, sino también tributarios; que el sistema necesita dialogar con los docentes, sabiendo oír sus deseos y aspiraciones, en la construcción del programa para que el mismo no sea estéril.

PALABRAS CLAVES: Formación continuada; imaginario social; educación física escolar. 


\section{REFERÊNCIAS}

ANDRÉ, M. Pesquisa em educação: buscando rigor e qualidade. Cadernos de Pesquisa, São Paulo, n. I|3, p. 51-64, jul. 200।.

AQUINO, J. G. Os mascates da formação contínua. Nova Escola, Brasília, v. 17, n. I 55, p. 14 , set. 2002 .

BARBIER, R. Sobre o imaginário. Em Aberto, Brasília, ano XIV, n. 6I , p. I 5-23, jan./mar. 1994.

BERGER, P L.; LUCKMANN, T. A construção social da realidade: tratado de sociologia do conhecimento. Petrópolis: Vozes, 2004.

BOGDAN, R.; BIKLEN, S. Investigação qualitativa em educação. Porto: Porto Editora, 1994.

CAPARRÓZ, F. E. Discurso e prática pedagógica: elementos para refletir sobre a complexa teia que envolve a educação física na dinâmica escolar. In: CAPARRÓZ, F. E. (org.). Educação física escolar: política, investigação e intervenção. Vitória: Proteoria, v. I, p. 193-2 |4, 200 I.

CAPARRÓZ, F. E.; BRACHT, V. O tempo e o lugar de uma didática da educação física. Revista Brasileira de Ciências do Esporte, Campinas, v. 28, n. 2, p. 21-37, jan. 2007.

CARVALHO, J. M.; SIMÕES, R. H. S. O processo de formação continuada de professores: uma construção estratégico-conceitual expressa nos periódicos. In: ANDRÉ, M. E. D. A. de (org.). Formação de Professores no Brasil (1990-1998). Brasília: Ministério da Educação e Cultura, p. |7|-|84, 2002.

CASTORIADIS, C. A instituição imaginária da sociedade. 3. ed. Rio de Janeiro: Editora Paz e Terra, 1982.

CASTORIADIS, C. La instituición imaginaria de la sociedad. In: COLOMBO, E. (org.). El imaginario social. Montevidéu: Nordan-Comunidad, p. 27-63, 1993.

COELHO, T. O imaginário e a pedagogia do telhado. Em Aberto, Brasília, ano XIV, n. 6I, p. I07-III, jan./mar. 1994.

COSTA, M. da S. Relações de trabalho e regimes de emprego no Canadá no Brasil: um estudo comparativo. In: CONGRESSO BRASILEIRO DE SOCIOLOGIA, I3. 2007, Recife. Anais... Recife: Universidade Federal de Pernambuco, 2007. Disponível em: <http://www. sbsociologia.com.br>. Acesso em: 30 ago. 2008.

DELBONI, T. M. Z. G. F. A formação continuada como lugares praticados: as reuniões de área no sistema de ensino de Vitória. 2006. Dissertação (Mestrado em Educação) - Programa de Pós-Graduação em Educação, Universidade Federal do Espírito Santo, Vitória, 2006.

FALSARELLA, A. M. Formação continuada e prática de sala de aula: os efeitos da formação continuada na atuação do professor. Campinas: Autores Associados, 2004. 
FERREIRA, S. A. S. A (re)mobilização sindical: da luta salarial às novas demandas da cidadania. In: CONGRESSO BRASILEIRO DE SOCIOLOGIA, I0., 200 I, Fortaleza. Anais... Fortaleza: Universidade Federal do Ceará, 2005. Disponível em: < http://sindicalismo.pessoal.bridge. com.br/SandroSbs200l.rtf>. Acesso em: 21 nov. 2008.

FERREIRA, N. T.; EIZIRIK, M. F. Educação e imaginário social: revendo a escola. Em Aberto, Brasília, ano XIV, n. 6I, p. 5-14, jan./mar. 1994.

FREITAS, H. C. L. de. Formação de professores no Brasil: 10 anos de embate entre projetos de formação. Educação \& Sociedade, Campinas, v. 23, n. 80, p. I36-167, set. 2002.

FREITAS, R. A. de. Sindicalismo, reforma da previdência e tempo de trabalho: o caso da CUT. In: CONGRESSO BRASILEIRO DE SOCIOLOGIA, I2., 2005, Belo Horizonte. Anais... Belo Horizonte: Universidade Federal de Minas Gerais, 2005. Disponível em: < http://www. sbsociologia.com.br/congresso/gt00.asp?idcongresso=4>. Acesso em: 30 ago. 2008.

GATTI, B. A. Implicações e perspectivas da pesquisa educacional no Brasil contemporâneo. Cadernos de Pesquisa, São Paulo, n. II3, p. 65-81, jul. 2001.

HERNÁNDEZ, F. A formação do professorado e a investigação sobre a aprendizagem dos docentes. In: MOLINA NETO, V.; TRIVIÑOS, A. N. S. (orgs.). A pesquisa qualitativa em educação fisica: alternativas metodológicas. 2. ed. Porto Alegre: Editora da UFRGS, p. 45 59, 2004.

MACEDO, R. S. A etnopesquisa crítica e multirreferencial nas ciências humanas e na educação. 2. ed. Salvador: Edufba, 2004.

MAYKUT, P.; MOREHOUSE, R. Investigación cualiativa: una guía práctica y filosófica. Barcelona: Hurtado Ediciones, 1999.

MOLINA, R. M. K.; MOLINA NETO, V. O pensamento dos professores de educação física sobre a formação permanente no contexto da Escola Cidadã: um estudo preliminar. Revista Brasileira de Ciências do Esporte, Campinas, v. 22, n. 3, p. 73-85, maio 2001.

MORGADO, J. C. Currículo e profissionalidade docente. Porto: Editora Porto, 2005.

MUGRÁBI, E. Formação continuada de professores em informática educativa no sistema municipal de Vitória: construindo práticas para a inserção na sociedade do conhecimento. 2005. Dissertação (Mestrado em Educação) - Programa de Pós-Graduação em Educação, Universidade Federal do Espírito Santo, Vitória, 2005.

NEGRINE, A. Instrumentos de coleta de informações na pesquisa qualitativa. In: MOLINA NETO, V.; TRIVIÑOS, A. N. S. (orgs.). A pesquisa qualitativa na educação física: alternativas metodológicas. Porto Alegre: UFRGS, Sulina, p. 61-94, 1999.

PALAFOX, G. U. M. PCTP: porque está sendo difícil implementar propostas críticas de ensino da educação física na escola. In: PALAFOX, G. U. M. et al. (org.). Planejamento 
coletivo do trabalho pedagógico - PCTP: a experiência partilhada. Uberlândia: Casa do Livro, p. I I-24, 2002.

SZYMANSKI, H. Entrevista reflexiva: um olhar psicológico sobre a entrevista em pesquisa. In: SZYMANSKI, H. (org.). A entrevista na pesquisa em educação: a prática reflexiva. Brasília: Liber Livro, p. 9-6I, 2004.

TAYLOR, S. J.; BOGDAN, R. Introducción a los métodos cualitativos de investigación: la búsqueda de significados. Barcelona: Paidós, 1987.

TERRA, D. V.; PIROLO, A. L. Saberes docentes e formação continuada de professores de educação física: a perspectiva da investigação-ação. EFdeportes.com. Buenos Aires, ano 10 , n. 93, fev. 2006. Disponível em: <http://www.efdeportes.com/efd93/docentes.htm>. Acesso em: 27 mar. 2007.

VITÓRIA, Secretaria Municipal de Educação. Plano municipal de educação de Vitória - ES: 200 I-2010, Vitória, 2003.

Recebido: 10 maio 2009

Aprovado: 18 fev. 2010

Endereço para correspondência

Walk Loureiro

Av. Roberto Simões Costa, n. 400, apto. 104

Ed. Costa Azul, Praia do Morro

Guarapari-ES

CEP 29216-100 